\title{
In Vitro Susceptibility to Ceftazidime/Avibactam and Comparators in Clinical Isolates of Enterobacterales from Five Latin American Countries
}

\author{
Tobias Manuel Appel ${ }^{1}\left(\mathbb{D}\right.$, María Fernanda Mojica ${ }^{1}{ }^{\mathbb{D}}$, Elsa De La Cadena ${ }^{1,2}$, \\ Christian José Pallares ${ }^{1,2,3}$, Marcela A. Radice ${ }^{4}$, Paulo Castañeda-Méndez ${ }^{5,6} \oplus$, \\ Diego A. Jaime-Villalón ${ }^{6}$, Ana C. Gales ${ }^{7}$, José M. Munita ${ }^{8}$ and María Virginia Villegas ${ }^{1,2,3, *}$ \\ 1 Grupo de Resistencia Antimicrobiana y Epidemiología Hospitalaria (RAEH), Universidad El Bosque, \\ Bogotá 110121, Colombia; tobiasm.appel@gmail.com (T.M.A.); Maria.MojicaMedina@va.gov (M.F.M.); \\ ecadenav@unbosque.edu.co (E.D.L.C.); icako@hotmail.com (C.J.P.) \\ 2 Grupo de Resistencia Bacteriana, Centro Internacional de Entrenamiento e Investigaciones \\ Médicas (CIDEIM), Cali 760031, Colombia \\ 3 Comité de Infecciones y Vigilancia Epidemiológica, Centro Médico Imbanaco, Cali 760043, Colombia \\ 4 Departamento de Microbiología, Inmunología, Biotecnología y Genética, Cátedra de Microbiología, \\ Universidad de Buenos Aires-CONICET, Buenos Aires C1113AAD, Argentina; mradice@ffyb.uba.ar \\ 5 Department of Infectious Diseases, Hospital Médica Sur, Ciudad de México 14050, Mexico; \\ drpaulocastanedam@hotmail.com \\ 6 Department of Infectious Diseases, Hospital San Angel Inn Universidad, Ciudad de México 03330, Mexico; \\ djaime_md@hotmail.com \\ 7 Department of Internal Medicine, Division of Infectious Diseases, Universidade Federal de São Paulo, \\ São Paulo 04039-032, Brazil; ana.gales@gmail.com \\ 8 Genomics and Resistant Microbes (GeRM) Group, Millennium Initiative for Collaborative Research On \\ Bacterial Resistance (MICROB-R), Santiago, Región Metropolitana 7650568, Chile; munita.jm@gmail.com \\ * Correspondence: mariavirginia.villegas@gmail.com
}

Received: 19 December 2019; Accepted: 23 January 2020; Published: 5 February 2020

\begin{abstract}
Background: High rates of resistance to third-generation cephalosporins and carbapenems in Enterobacterales have been reported in Latin America. Ceftazidime/avibactam (CZA) is the combination of a third-generation cephalosporin and a non- $\beta$-lactam $\beta$-lactamase inhibitor, which has shown activity against isolates producing class $A, C$ and $D \beta$-lactamases. Herein, we evaluated the activity of CZA and comparators against clinical isolates of Enterobacterales in Latin America. Methods: The activity of CZA and comparators was evaluated against clinical isolates of Enterobacterales from Argentina, Brazil, Chile, Colombia and Mexico that were collected between January 2016 and October 2017. One specific phenotypic subset was evaluated. A carbapenem non-susceptible (CNS) phenotype was defined as any isolate displaying a minimum inhibitory concentration (MIC) $\geq 1$ $\mathrm{mg} / \mathrm{L}$ for ertapenem. Results: CZA was active against $95.8 \%$ of all isolates and $77.5 \%$ of CNS isolates. Fosfomycin (FOS) and tigecycline (TGC) were the second most active antibiotics with $93.4 \%$ of Enterobacterales being susceptible. Conclusions: The results of this study underline the potential therapeutic role of CZA in Latin America.
\end{abstract}

Keywords: Antimicrobial activity; Argentina; Brazil; Chile; Colombia; Mexico

\section{Introduction}

Antimicrobial resistance is a threat to public health. Enterobacterales are some of the most common and pathogenic microorganisms that have acquired resistance to several classes of antimicrobials [1]. Particularly concerning is the resistance to carbapenems since these agents are often considered the last 
resort antibiotics. In addition, infections caused by carbapenem-resistant enterobacteria are associated with higher costs and mortality rates [2,3].

The most frequently found carbapenem resistance mechanism is the production of carbapenemases, among which Klebsiella pneumoniae carbapenemases (KPC) are the most widely distributed worldwide and are endemic in several countries of the Latin American region [4]. Ceftazidime/avibactam (CZA) is the combination of a third-generation cephalosporin and a non- $\beta$-lactam inhibitor capable of inhibiting several class D, C and A $\beta$-lactamases, including the KPC-family enzymes. Several in vitro, in vivo and clinical studies have reported favorable results with CZA against carbapenemase-producing enterobacteria, while being less toxic than other agents commonly used to treat carbapenem-resistant bacteria, such as colistin and aminoglycosides [5-7].

Herein, we evaluated the activity of CZA and comparators against 2252 clinical isolates of Enterobacterales from 20 healthcare institutions located in Argentina, Brazil, Chile, Colombia, and Mexico between January 2016 and October 2017.

\section{Results}

The distribution of the 2252 isolates of Enterobacterales per country and species is shown in Table 1. Overall, 95.8\% (2158/2252) of the isolates were susceptible to CZA (minimum inhibitory concentration of $90 \%$ of isolates $\left(\mathrm{MIC}_{90}\right) \leq 1 \mathrm{mg} / \mathrm{L}$ ). The highest susceptibility was observed in Escherichia coli $(97.9 \%)$, followed by Serratia marcescens (94.5\%), Klebsiella aerogenes (93.3\%), Klebsiella pneumoniae (92.1\%) and isolates of the Enterobacter cloacae complex with a susceptibility of $92.0 \%$ (Table 2). Fosfomycin (FOS) and tigecycline (TGC) were the second most active antibiotics with $93.4 \%$ of Enterobacterales susceptible, followed by the carbapenems meropenem (MEM) (88.7\%), imipenem (IMI) $(87.1 \%)$ and ertapenem (ETP) $(82.4 \%)$.

Table 1. Susceptibility of Enterobacterales to ceftazidime/avibactam and comparators by country.

\begin{tabular}{|c|c|c|c|c|c|c|c|c|c|c|}
\hline \multirow{2}{*}{ Microorganism } & \multirow{2}{*}{ Number of Isolates } & \multicolumn{9}{|c|}{ Percentage of Susceptibility } \\
\hline & & CZA & CAZ & FEP & TZP & ETP & IMI & MEM & TGC & FOS \\
\hline Argentina & 233 & & & & & & & & & \\
\hline E. coli & 160 & 97.5 & 53.8 & 91.3 & 60 & 95.6 & 96.3 & 96.9 & 98.1 & 98.1 \\
\hline CNS & 7 & 57.1 & 0 & 14.3 & 14.3 & - & 14.3 & 28.6 & 28.6 & 57.1 \\
\hline K. pneumoniae & 65 & 98.5 & 52.3 & 61.5 & 49.2 & 81.5 & 87.7 & 89.2 & 93.8 & 96.9 \\
\hline CNS & 12 & 100 & 8.3 & 8.3 & 8.3 & - & 33.3 & 41.7 & 75 & 91.7 \\
\hline E. cloacae complex & 4 & 100 & 75 & 75 & 75 & 75 & 75 & 75 & 75 & 75 \\
\hline CNS & 0 & & & & & & & & & \\
\hline S. marcescens & 4 & 75 & 75 & 75 & 75 & 75 & 75 & 75 & 75 & 75 \\
\hline CNS & 1 & 0 & 0 & 0 & 0 & - & 0 & 0 & 0 & 0 \\
\hline Brazil & 85 & & & & & & & & & \\
\hline E. coli & 20 & 95 & 65 & 65 & 80 & 70 & 75 & 75 & 90 & 100 \\
\hline CNS & 6 & 83.3 & 14.3 & 14.3 & 42.9 & - & 14.3 & 14.3 & 57.1 & 85.7 \\
\hline K. pneumoniae & 23 & 87 & 4.3 & 8.7 & 13 & 21.7 & 17.4 & 21.7 & 73.9 & 95.7 \\
\hline CNS & 18 & 83.3 & 0 & 0 & 0 & - & 0 & 0 & 66.7 & 94.4 \\
\hline E. cloacae complex & 24 & 100 & 25 & 29.2 & 58.3 & 62.5 & 83.3 & 87.5 & 79.2 & 79.2 \\
\hline $\mathrm{CNS}$ & 9 & 100 & 0 & 11.1 & 44.4 & - & 66.7 & 55.6 & 66.7 & 77.8 \\
\hline S. marcescens & 18 & 100 & 100 & 61.1 & 66.7 & 83.3 & 88.9 & 83.3 & 88.9 & 83.3 \\
\hline CNS & 2 & 100 & 0 & 0 & 0 & - & 0 & 0 & 50 & 100 \\
\hline Chile & 443 & & & & & & & & & \\
\hline E. coli & 347 & 99.1 & 70.3 & 76.7 & 91.1 & 88.8 & 94.2 & 96.5 & 94.5 & 94.8 \\
\hline CNS & 39 & 94.9 & 23.1 & 25.6 & 51.3 & - & 53.8 & 69.2 & 59 & 92.3 \\
\hline K. pneumoniae & 66 & 98.5 & 43.9 & 51.5 & 60.6 & 78.8 & 90.9 & 83.3 & 93.9 & 90.9 \\
\hline CNS & 14 & 92.9 & 0 & 0 & 14.3 & - & 57.1 & 21.4 & 92.9 & 71.4 \\
\hline E. cloacae complex & 21 & 100 & 81 & 100 & 90.5 & 90.5 & 100 & 100 & 95.2 & 85.7 \\
\hline CNS & 2 & 100 & 100 & 100 & 50 & - & 100 & 100 & 100 & 100 \\
\hline S. marcescens & 9 & 100 & 66.7 & 66.7 & 77.8 & 66.7 & 100 & 88.9 & 100 & 100 \\
\hline CNS & 3 & 100 & 33.3 & 33.3 & 33.3 & - & 100 & 66,7 & 100 & 100 \\
\hline
\end{tabular}


Table 1. Cont.

\begin{tabular}{cccccccccccc}
\hline \multirow{2}{*}{ Microorganism } & Number of Isolates & \multicolumn{10}{c}{ Percentage of Susceptibility } \\
\cline { 3 - 11 } & & CZA & CAZ & FEP & TZP & ETP & IMI & MEM & TGC & FOS \\
\hline Colombia & 1396 & & & & & & & & & \\
E. coli & 813 & 97.3 & 79.3 & 81.8 & 91.4 & 90.7 & 94.7 & 95.1 & 96.1 & 94.1 \\
CNS & 76 & 72.4 & 0 & 0 & 0 & - & 44.7 & 47.4 & 64.5 & 76.3 \\
K. pneumoniae & 441 & 90.2 & 52.4 & 56.7 & 61.7 & 68.9 & 74.1 & 76.2 & 91.2 & 91.6 \\
CNS & 137 & 68.6 & 0 & 0 & 0 & - & 18.2 & 23.4 & 73 & 80.3 \\
E. cloacae complex & 82 & 87.8 & 47.6 & 47.6 & 54.9 & 58.5 & 78 & 78 & 90.2 & 80.5 \\
CNS & 34 & 73.5 & 11.8 & 11.8 & 20.6 & - & 29.4 & 38.2 & 76.5 & 70.6 \\
S. marcescens & 60 & 93.3 & 61.7 & 63.3 & 63.3 & 65 & 66.7 & 73.3 & 76.7 & 93.3 \\
CNS & 21 & 81 & 4.8 & 4.8 & 19 & - & 19 & 23.8 & 52.4 & 81 \\
\hline Mexico & 95 & & & & & & & & & \\
E. coli & 69 & 100 & 34.8 & 39.1 & 73.9 & 87 & 91.3 & 97.1 & 95.7 & 94.2 \\
CNS & 9 & 100 & 11.1 & 0 & 11.1 & - & 44.4 & 77.8 & 66.7 & 11.1 \\
K. pneumoniae & 15 & 100 & 66.7 & 66.7 & 40 & 86.7 & 86.7 & 86.7 & 100 & 100 \\
CNS & 2 & 100 & 0 & 0 & 0 & - & 50 & 50 & 100 & 100 \\
E. cloacae complex & 11 & 90.9 & 27.3 & 18.2 & 9.1 & 63.6 & 18.2 & 72.7 & 90.9 & 100 \\
CNS & 4 & 75 & 0 & 0 & 0 & - & 25 & 25 & 100 & 100 \\
\hline
\end{tabular}

CAZ: ceftazidime; CZA: ceftazidime/avibactam; ETP: ertapenem; FEP: cefepime; FOS: fosfomycin; IMI: imipenem; MEM: meropenem; TGC: tigecycline; TZP: piperacillin/tazobactam

In all five countries, the susceptibility of Enterobacterales to CZA was similarly high, ranging from 99.1\% in Chile ( $\left.\mathrm{MIC}_{90} \leq 1 \mathrm{mg} / \mathrm{L}\right), 98.9 \%$ in Mexico $\left(\mathrm{MIC}_{90} \leq 1 \mathrm{mg} / \mathrm{L}\right), 97.4 \%$ in Argentina $\left(\mathrm{MIC}_{90} \leq 1 \mathrm{mg} / \mathrm{L}\right.$ ), $96.5 \%$ in Brazil (minimum inhibitory concentration of $50 \%$ of isolates $\left(\mathrm{MIC}_{50}\right) \leq 1 \mathrm{mg} / \mathrm{L}, \mathrm{MIC}_{90} 2 \mathrm{mg} / \mathrm{L}$ ) to $94.3 \%$ in Colombia ( $\mathrm{MIC}_{50} \leq 1 \mathrm{mg} / \mathrm{L}, \mathrm{MIC}_{90} 2 \mathrm{mg} / \mathrm{L}$ ). Comparable results were observed for FOS $(92.5 \%-97.4 \%)$ and TGC (81.5\%-95.8\%). For carbapenem non-susceptible (CNS) Enterobacterales, CZA was active against $77.5 \%$ of all tested strains ( $\mathrm{MIC}_{50} 2 \mathrm{mg} / \mathrm{L}, \mathrm{MIC}_{90} \geq 128 \mathrm{mg} / \mathrm{L}$ ). The activity of CZA was the highest in CNS isolates from Chile $\left(94.8 \%, \mathrm{MIC}_{50} 2 \mathrm{mg} / \mathrm{L}, \mathrm{MIC}_{90} 8 \mathrm{mg} / \mathrm{L}\right)$, followed by Mexico $\left(93.3 \%, \mathrm{MIC}_{50} \leq 1 \mathrm{mg} / \mathrm{L}, \mathrm{MIC}_{90} 1 \mathrm{mg} / \mathrm{L}\right)$, Brazil $\left(88.6 \%, \mathrm{MIC}_{50} \leq 1 \mathrm{mg} / \mathrm{L}, \mathrm{MIC}_{90} 32 \mathrm{mg} / \mathrm{L}\right)$, Argentina $(80 \%$, $\left.\mathrm{MIC}_{50} \leq 1 \mathrm{mg} / \mathrm{L}, \mathrm{MIC}_{90} 64 \mathrm{mg} / \mathrm{L}\right)$, and Colombia $\left(71.3 \%, \mathrm{MIC}_{50} 2 \mathrm{mg} / \mathrm{L}, \mathrm{MIC}_{90} \geq 128 \mathrm{mg} / \mathrm{L}\right)$ (Table 1).

For all species of Enterobacterales, regardless of their susceptibility profile, CZA was the compound with the highest activity when compared with other $\beta$-lactam agents. For isolates of $E$. coli and E. cloacae complex, CZA was superior to all other antimicrobials tested. In the case of K. pneumoniae and K. aerogenes, the activity of FOS was slightly superior to CZA, whereas for S. marcescens both antimicrobials showed a susceptibility of $94.5 \%$.

From the 2252 isolates tested, 396 (17.6\%) were found to be CNS; of note, $46.2 \%$ were identified as K. pneumoniae. CZA was active against $77.5 \%$ of the CNS isolates $\left(\mathrm{MIC}_{50} 2 \mathrm{mg} / \mathrm{L}, \mathrm{MIC}_{90} \geq 128 \mathrm{mg} / \mathrm{L}\right.$ ), with the highest activity against $S$. marcescens $(81.5 \%)$, while the lowest susceptibility was observed for K. pneumoniae (74.3\%). For this group, the activity of CZA was superior to all $\beta$-lactams and superior or equal to that of FOS for isolates of E. cloacae complex, K. aerogenes and S. marcescens. 
Table 2. Susceptibility of Enterobacterales to ceftazidime/avibactam according to minimum inhibitory concentration (MIC) (mg/L) distribution and susceptibility to comparators.

\begin{tabular}{|c|c|c|c|c|c|c|c|c|c|c|c|c|c|c|c|c|c|c|c|c|}
\hline \multirow{3}{*}{ Microorganism } & \multirow{3}{*}{ Number of Isolates } & \multicolumn{11}{|c|}{ Ceftazidime/Avibactam } & \multirow{2}{*}{\multicolumn{8}{|c|}{$\begin{array}{l}\text { Susceptibility to Comparators (\% Isolates } \\
\text { Susceptible) }\end{array}$}} \\
\hline & & \multicolumn{11}{|c|}{ Cumulative Percentage of Isolates at Each MIC (mg/L) } & & & & & & & & \\
\hline & & $\leq \mathbf{1}$ & 2 & 4 & 8 & 16 & 32 & 64 & $\geq \mathbf{1 2 8}$ & $\mathrm{MIC}_{50}$ & $\mathrm{MIC}_{90}$ & $\% \mathrm{~S}$ & CAZ & FEP & TZP & ETP & IMI & MEM & I TGC & FOS \\
\hline Enterobacterales & 2252 & 89 & 93.8 & 95.2 & 95.8 & 96.1 & 96.9 & 97.7 & 100 & $\leq 1$ & 2 & 95.8 & 64 & 67.7 & 79 & 82.4 & 87.1 & 88.7 & 93.4 & 93.4 \\
\hline CNS & 396 & 44.7 & 66.9 & 74.7 & 77.5 & 78.8 & 83.1 & 87.6 & 100 & 2 & $\geq 128$ & 77.5 & 8.6 & 12.1 & 26.8 & - & 31.6 & 35.9 & 68.9 & 81.3 \\
\hline E. coli & 1409 & 93.4 & 96.9 & 97.6 & 97.9 & 98.2 & 98.5 & 99 & 100 & $\leq 1$ & $\leq 1$ & 97.9 & 71.8 & 75.7 & 90.3 & 90.3 & 91.8 & 95.5 & 95.6 & 94.8 \\
\hline CNS & 137 & 43.8 & 70.1 & 77.4 & 80.3 & 81.8 & 84.7 & 89.1 & 100 & 2 & $\geq 128$ & 80.3 & 16.8 & 21.9 & 46.7 & - & 44.5 & 53.3 & 61.3 & 82.5 \\
\hline K. pneumoniae & 610 & 81.8 & 88.2 & 91 & 92.1 & 92.4 & 93.9 & 95.4 & 100 & $\leq 1$ & 4 & 92.1 & 50 & 53.4 & 59.2 & 70 & 75.6 & 76.6 & 91.3 & 92.5 \\
\hline CNS & 183 & 45.4 & 62.9 & 71.6 & 74.3 & 75.4 & 80.3 & 85.2 & 100 & 2 & $\geq 128$ & 74.3 & 2.7 & 4.9 & 13.7 & - & 20.8 & 22.4 & 74.3 & 82 \\
\hline CNS & 41 & 46.3 & 70.7 & 75.6 & 80.5 & 80.5 & 90.3 & 92.7 & 100 & 2 & 32 & 80.5 & 7.3 & 14.6 & 19.5 & - & 39 & 43.9 & 80.5 & 73.2 \\
\hline K. aerogenes & 30 & 86.7 & 90 & 93.3 & 93.3 & 96.6 & 96.6 & 100 & 100 & $\leq 1$ & 2 & 93.3 & 66.7 & 70 & 83.3 & 73.3 & 83.3 & 83.3 & 90 & 96.7 \\
\hline CNS & 8 & 50 & 62.5 & 75 & 75 & 87.5 & 87.5 & 100 & 100 & $\leq 1$ & 64 & 75 & 12.5 & 12.5 & 50 & - & 37.5 & 37.5 & 50 & 75 \\
\hline S. marcescens & 91 & 81.3 & 92.3 & 94.5 & 94.5 & 94.5 & 94.5 & 95.6 & 100 & $\leq 1$ & 2 & 94.5 & 62.6 & 64.8 & 69.2 & 70.3 & 73.6 & 78 & 80.2 & 94.5 \\
\hline CNS & 27 & 40.7 & 74 & 81.4 & 81.4 & 81.4 & 81.4 & 85.1 & 100 & 2 & $\geq 128$ & 81.5 & 7.4 & 7.4 & 18.5 & - & 25.9 & 25.9 & 55.6 & 81.5 \\
\hline
\end{tabular}

: ceftazidime; CZA: ceftazidime/avibactam; ETP: ertapenem; FEP: cefepime; FOS: fosfomycin; IMI: imipenem; MEM: meropenem; MIC ${ }_{50}$ : minin 


\section{Discussion}

This study showed that $95.8 \%$ of clinical isolates of Enterobacterales from five Latin American countries, collected between January 2016 and October 2017, were susceptible to CZA (MIC $90 \leq 1 \mathrm{mg} / \mathrm{L}$ ). The susceptibility to CZA between species ranged from $97.9 \%$ for E. coli to $92.0 \%$ for isolates of E. cloacae complex. Furthermore, $77.5 \%$ of CNS isolates remained susceptible to CZA. These results underline the potential therapeutic role of CZA for patients infected with KPC-producing and other carbapenemase-producing enterobacteria, which are prevalent in the Latin American region [4,7].

Although the present study might be limited by the small number of isolates from Mexico and Brazil and the fact that they are from a single center in Argentina, Brazil and Mexico, our results are similar to most reports described previously by other authors. In a study by Flamm et al. [8], CZA was evaluated against 130 clinical urinary isolates of Enterobacterales collected in 2011 from Argentina, Brazil, Chile, Colombia, Mexico, Panama and Venezuela, finding a MIC90 of $0.25 \mathrm{mg} / \mathrm{L}$. Of the evaluated strains, $0.8 \%$ were resistant to MEM. Similarly, Karlowsky et al. [9] evaluated the activity of CZA and comparators against clinical isolates of Enterobacterales and P. aeruginosa collected between 2012 and 2015 from six Latin American countries (Argentina, Brazil, Chile, Colombia, Mexico and Venezuela). In this study, CZA was active against $99.7 \%$ of 7665 Enterobacterales, which is similar to our findings. Furthermore, 5.1\% of all isolates were carbapenem (MEM) non-susceptible. In the MEM non-susceptible subgroup, the authors observed that CZA was active against 95.4\% of isolates, which is significantly higher compared to our observations.

The differences in CZA susceptibility of the non-susceptible subgroups could be explained by the different hospitals and geographical areas included in the study, as well as the changes in the epidemiology of resistance mechanisms between the study periods. For example, in the case of Brazil, susceptibility rates to CZA in this study were inferior to those observed previously against K. pneumoniae isolates in a surveillance study by Rossi et al. (100\% susceptible) [10]. An increase in class B $\beta$-lactamases (which were detected in $0.2 \%$ of all Enterobacterales by Karlowsky et al.) or the emergence of different mechanisms of resistance to CZA in class A $\beta$-lactamase-producing K. pneumoniae as reported in the literature could explain this difference [11,12].

\section{Materials and Methods}

Isolates were collected in each of the participating institutions between January 2016 and October 2017. Upon reception, species confirmation was performed using matrix-assisted laser desorption/ionization time-of-flight mass spectrometry (Biomeriéux, Marcy-l'Étoile, France). Susceptibility testing was performed in the laboratory of the research group Resistencia Antimicrobiana y Epidemiología Hospitalaria (RAEH), Universidad El Bosque, Bogotá, Colombia. Minimum inhibitory concentrations (MICs) were determined by broth microdilution using customized Sensititre plates (TREK Diagnostic Systems, East Grinstead, West Sussex, UK), with E. coli ATCC 25922 as quality control, following Clinical and Laboratory Standards Institute (CLSI) guidelines [13]. Antibiotics evaluated included: ceftazidime/avibactam (CZA; 1/4-128/4 mg/L), ceftazidime (CAZ; 2-32 mg/L), cefepime (FEP; 2-64 mg/L), piperacillin/tazobactam (TZP; 2/4-128/4 mg/L), ertapenem (ETP; 0.25-32 mg/L), imipenem (IMP; 0.25-128 mg/L), meropenem (MEM; 0.25-128 mg/L), tigecycline (TGC; 0.25-8 mg/L) and fosfomycin (FOS; 8-128 mg/L). With the exception of FOS and TGC, results were interpreted according to the CLSI 2018 breakpoints [14]. FOS breakpoints for Enterobacterales were extrapolated from the E. coli breakpoint by CLSI (FOS non-susceptible MIC $\geq 128 \mathrm{mg} / \mathrm{L}$ ). United States Food and Drug Administration product package insert criteria were used as breakpoints for TGC (susceptible: $\leq 2 \mathrm{mg} / \mathrm{L}$; intermediate: $4 \mathrm{mg} / \mathrm{L}$; resistant: $\geq 8 \mathrm{mg} / \mathrm{L}$ ) [15]. The specific phenotypic subset defined as a carbapenem non-susceptible (CNS) phenotype included isolates displaying a MIC $\geq 1 \mathrm{mg} / \mathrm{L}$ for ETP. 


\section{Conclusions}

We report excellent activity of CZA against diverse Enterobacterales collected in Latin America. The lower rates of CZA susceptibility among CNS isolates in our study highlights the importance of active surveillance programs in order to follow the evolution of resistance mechanisms against the antibiotic armamentarium, including newly introduced antimicrobial agents.

Author Contributions: Conceptualization, M.F.M., E.D.L.C., C.J.P. and M.V.V.; Methodology, E.D.L.C. and M.F.M.; Validation, M.F.M. and M.V.V.; Formal Analysis, T.M.A., M.F.M. and E.D.L.C.; Investigation, E.D.L.C., M.F.M., M.A.R., P.C.-M., D.A.J.-V., A.C.G. and J.M.M.; Data Curation, E.D.L.C. and C.J.P.; Writing-Original Draft Preparation, T.M.A.; Writing-Review and Editing, M.F.M., E.D.L.C., C.J.P., M.A.R., P.C.-M., D.A.J.-V., A.C.G., J.M.M. and M.V.V.; Supervision, E.D.L.C., M.A.R., P.C.-M., D.A.J.-V., A.C.G. and J.M.M.; Project Administration, E.D.L.C. All authors have read and agreed to the published version of the manuscript.

Funding: This research received no external funding.

Conflicts of Interest: C.J.P. and M.V.V. have received consulting fees and/or research grants from Merck Sharp and Dohme, WEST and GPC pharma. All other authors declare no competing interests.

$\begin{array}{ll}\text { Abbreviations } \\ \text { CAZ } & \text { Ceftazidime } \\ \text { CNS } & \text { Carbapenem non-susceptible } \\ \text { CZA } & \text { Ceftazidime/avibactam } \\ \text { ETP } & \text { Ertapenem } \\ \text { FEP } & \text { Cefepime } \\ \text { FOS } & \text { Fosfomycin } \\ \text { IMI } & \text { Imipenem } \\ \text { MEM } & \text { Meropenem } \\ \text { MIC } & \text { Minimum inhibitory concentration } \\ \text { TGC } & \text { Tigecycline } \\ \text { TZP } & \text { Piperacillin/tazobactam }\end{array}$

\section{References}

1. Iredell, J.; Brown, J.; Tagg, K. Antibiotic Resistance in Enterobacteriaceae: Mechanisms and Clinical Implications. BMJ 2016, 8, 352. [CrossRef] [PubMed]

2. Falagas, M.E.; Tansarli, G.S.; Karageorgopoulos, D.E.; Vardakas, K.Z. Deaths Attributable to Carbapenem-Resistant Enterobacteriaceae Infections. Emerg. Infect. Dis. 2014, 20, 1170-1175. [CrossRef] [PubMed]

3. Bartsch, S.M.; McKinnell, J.A.; Mueller, L.E.; Miller, L.G.; Gohil, S.K.; Huang, S.S.; Lee, B.Y. Potential Economic Burden of Carbapenem-Resistant Enterobacteriaceae (CRE) in the United States. Clin. Microbiol. Infect. 2017, 23, 48.e9-48.e16. [CrossRef] [PubMed]

4. Logan, L.K.; Weinstein, R.A. The Epidemiology of Carbapenem-Resistant Enterobacteriaceae: The Impact and Evolution of a Global Menace. J. Infect. Dis. 2017, 215 (Suppl. 1), S28-S36. [CrossRef] [PubMed]

5. Keepers, T.R.; Gomez, M.; Celeri, C.; Nichols, W.W.; Krause, K.M. Bactericidal Activity, Absence of Serum Effect, and Time-kill Kinetics of Ceftazidime-Avibactam against $\beta$-lactamase-Producing Enterobacteriaceae and Pseudomonas aeruginosa. Antimicrob. Agents Chemother. 2014, 58, 5297-5305. [CrossRef] [PubMed]

6. Zasowski, E.J.; Rybak, J.M.; Rybak, M.J. The $\beta$-Lactams Strike Back: Ceftazidime-Avibactam. Pharmacotherapy 2015, 35, 755-770. [CrossRef] [PubMed]

7. Karaiskos, I.; Lagou, S.; Pontikis, K.; Rapti, V.; Poulakou, G. The "Old" and the "New" Antibiotics for MDR Gram-Negative Pathogens: For Whom, When, and How. Front Public Health 2019, 7, 151:1-151:25. [CrossRef] [PubMed]

8. Flamm, R.K.; Sader, H.S.; Farrell, D.J.; Jones, R.N. Ceftazidime-Avibactam and Comparator Agents Tested against Urinary Tract Isolates from a Global Surveillance Program (2011). Diagn. Microbiol. Infect. Dis. 2014, 80, 233-238. [CrossRef] [PubMed] 
9. Karlowsky, J.A.; Kazmierczak, K.M.; Bouchillon, S.K.; de Jonge, B.L.M.; Stone, G.G.; Sahm, D.F. In Vitro Activity of Ceftazidime-Avibactam against Clinical Isolates of Enterobacteriaceae and Pseudomonas aeruginosa Collected in Latin American Countries: Results from the INFORM Global Surveillance Program, 2012 to 2015. Antimicrob. Agents Chemother. 2019, 63. [CrossRef] [PubMed]

10. Rossi, F.; Cury, A.P.; Franco, M.R.G.; Testa, R.; Nichols, W.W. The In Vitro Activity of Ceftazidime-Avibactam against 417 Gram-Negative Bacilli Collected in 2014 and 2015 at a Teaching Hospital in São Paulo, Brazil. Braz. J. Infect. Dis. 2017, 21, 569-573. [CrossRef] [PubMed]

11. Nelson, K.; Hemarajata, P.; Sun, D.; Rubio-Aparicio, D.; Tsivkovski, R.; Yang, S.; Sebra, R.; Kasarskis, A.; Nguyen, H.; Hanson, B.M.; et al. Resistance to Ceftazidime-Avibactam Is Due to Transposition of KPC in a Porin-Deficient Strain of Klebsiella pneumoniae with Increased Efflux Activity. Antimicrob. Agents Chemother. 2017, 61, e00989:1-e00989:13. [CrossRef] [PubMed]

12. Shields, R.K.; Chen, L.; Cheng, S.; Chavda, K.D.; Press, E.G.; Snyder, A.; Pandey, R.; Doi, Y.; Kreiswirth, B.N.; Nguyen, M.H.; et al. Emergence of Ceftazidime-Avibactam Resistance Due to Plasmid-Borne $b l_{\mathrm{KPC}-3}$ Mutations during Treatment of Carbapenem-Resistant Klebsiella pneumoniae Infections. Antimicrob. Agents Chemother. 2017, 61, e02097:1-e02097:11.

13. CLSI. Methods for Dilution Antimicrobial Susceptibility Tests for Bacteria That Grow Aerobically; Approved Standard-Thenth Edition; CLSI Document M07-A10; Clinical and Laboratory Standards Institute: Wayne, PA, USA, 2015.

14. CLSI. Performance Standards for Antimicrobial Susceptibility Testing, 28th ed.; CLSI Supplement M100; Clinical and Laboratory Standards Institute: Wayne, PA, USA, 2018.

15. Pfizer. Tygacil ${ }^{\circledR}$ (Tigecycline) Injection, Powder, Lyophilized, for Solution, Prescribing Information; Pfizer Inc.: Philadelphia, PA, USA, 2019.

(C) 2020 by the authors. Licensee MDPI, Basel, Switzerland. This article is an open access article distributed under the terms and conditions of the Creative Commons Attribution (CC BY) license (http://creativecommons.org/licenses/by/4.0/). 